\section{O vigor crítico da sagesse montaigniana}

Silvana de Souza Ramos*

Resumo: O pensamento renascentista foi responsável por uma vigorosa reflexão sobre a posição metafísica do homem no cosmos e sobre o papel da ação no interior da vida social. Tendo em vista este contexto, nosso artigo pretende discutir o pensamento de Montaigne, tanto no que se refere a sua filiação às pretensões humanistas, quanto no que diz respeito às divergências que o separam dessa vertente (em suas diversas nuances), especialmente aquelas que permitiram o engendramento da manière peculiar ao filósofo a forma ensaio. Isto nos permitirá, ademais, refletir sobre o potencial crítico do ensaísmo frente a alguns valores da Modernidade.

Palavras-chaves: Montaigne, humanismo, Renascimento, ensaio, crítica.

A tarefa de decifrar qual o significado do humanismo na filosofia de Montaigne é bastante ingrata. A começar pelo fato de que não há consenso nem mesmo a respeito do que seja - num sentido mais amplo - o humanismo renascentista. Seguindo P. O. Kristeller, a expressão humanismo foi cunhada no início do século XIX, embora o termo humanista (humanista) remonte ao século XV tardio, tendo sido de uso corrente no século XVI. O humanista era um mestre ou representante profissional das humanidades os studia humanitatis - que compreendiam cinco disciplinas: gramática, retórica, poética, história e filosofia moral (Kristeller 11, p. 194-5). Neste sentido, Montaigne estaria longe de ser um humanista, visto que se recusava a caracterizar os Ensaios como uma obra de especialista, e insistia em dizer que nunca projeto semelhante, o de "pintar a si mesmo", fora levado a cabo anteriormente.

Na contracorrente da perspectiva de P. O. Kristeller, Eugenio Garin se nega a reduzir o humanismo ao trabalho dos profissionais das humanidades, pois isto significaria, por um lado, minimizar a ruptura que o Renascimento representou em relação aos valores da Idade Média, e, por outro, reduzir o trabalho dos humanistas a um "mero fato escolar ou literário" (Garin 6, p. 83-4). Mas, a despeito desta discordância, * Doutoranda em Filosofia pelo Depto. de Filosofia da USP. os autores aceitam que o pensamento produzido na Renascença foi responsável por uma vigorosa reflexão sobre a posição metafísica do homem no cosmos, e por uma avaliação do papel da ação do homem na sociedade, o que nos permite encontrar, ainda que em chave diversa, as preocupações de Montaigne em consonância com as investigações do humanismo. Segundo P. O. Kristeller, o saber humanista, se não produziu um corpo de idéias sistemáticas, "teve um efeito fermentador no campo do pensamento moral, e proporcionou um grande conjunto de idéias seculares que haveriam de influir nos séculos seguintes, e que de nenhuma maneira foram eliminadas pela Reforma" (Kristeller 11, p. 202). E, de acordo com as análises de Eugenio Garin, foi no Renascimento que entramos em contado com o momento em que se afirmaram as exigências mais vivas de nossa cultura, isto é, “a preocupação de nos definirmos através do 'outro', a aquisição do sentido da história, que se confunde com o sentido do tempo, e o fato de considerar a história e o tempo como dimensões próprias da condição humana" (Garin 6, p. 87).

Neste sentido mais amplo, os homens da Renascença se relacionavam com os autores do passado - se quisermos sintetizar numa palavra - de maneira crítica. Ao mesmo tempo em que as categorias medievais lhes pareciam insuficientes e insustentáveis, o encontro com o passado clássico, do qual se reivindicavam herdeiros legítimos, possibilitava a emergência de uma nova maneira de conceber o homem:

Descoberta e restauração do pensamento antigo, esta nova reflexão aparece não como uma confusão com seu objeto mas como um colocar-se à distância. Ela se aplica em definir, por uma démarche que lhe é própria, a verdadeira relação, novamente descoberta, entre o eu e o objeto, entre o homem e o mundo histórico que o modela, ao qual ele se opõe, e no contato com o qual se descobre ou se forma (Idem, p. 86-7)

A reflexão sobre a natureza do homem se insere, portanto, nessa lógica. Quer dizer, embora ela não seja propriamente original (visto que suas fontes são a Bíblia, a patrística e, evidentemente, os clássicos gregos e romanos), o Renascimento, ao retomá-la, "caracterizou-se por um incremento e intensificação na pesquisa da natureza do homem" (Kraye 10, p. 306) 
Exemplo disso é o pensamento de Marsílio Ficino no qual a glorificação do homem assume um significado filosófico definido. A partir de uma revisão do esquema plotiniano, Ficino enfatiza dois aspectos principais: a universalidade do homem e sua posição central no universo. Nesse intuito, o autor formula que "a alma é verdadeiramente o meio de todas as coisas criadas por Deus (...). Está no centro entre os seres mais altos e os mais baixos" (Kristeller 11, p. 63-4.). Em outros termos, o neoplatonismo de Ficino entendia o homem como ligação ontológica - vinculum mundi - entre os mundos material e inteligível. Na esteira desta formulação, surge o pensamento de Pico della Mirandola. O autor compartilha com Ficino a idéia de que o homem é um microcosmo onde todas as formas de vida estão contidas. Todavia, em seu Discurso sobre a Dignidade do Homem, o autor "remove o homem do centro da hierarquia Neoplatônica e lhe dá um estatuto ontológico indeterminado" (Kraye 10, p.313). Segundo Pico della Mirandola, Deus, após construir o universo e estabelecer os atributos e o lugar devido a cada criatura, precisava ainda definir os dons do homem - "sua última obra". Naquele que estava destinado "a louvar nos outros a liberalidade divina", e que não poderia receber nenhum dos bens particulares já distribuídos à criação, foram concedidos todos os dons. Posto no "meio do mundo", o homem, segundo seu "grau de arbítrio", deveria conquistar um determinado estatuto ontológico. No exercício de sua liberdade, cultivando as "sementes de toda espécie e germes de toda vida" (Mirandolla 17, p. 51-3), ele realizaria sua humanidade através da cultura, "no esforço de humanização que enreda a natureza em seu movimento" (Cardoso 3, p. 47). O Discurso de Pico sintetiza, no seu radical elogio da dignitas hominis, os ideais de uma época: "A celebração das prerrogativas do homem é para tantos renascentistas chamamento para a realização de sua verdadeira essência, para a instauração de uma humanitas que subtrai à barbárie por meio do estudo e do cultivo" (Idem, p. 47).

Ora, o adiantamento crítico de Montaigne em relação a tais ideais é notado por muitos de seus leitores. É certo que compartilha com seus antecessores renascentistas a paixão pelas letras clássicas atada à reflexão em torno da vida moral. É certo também que o ensaísta coloca o homem no centro de suas investigações. Entretanto, à “fé de seus contemporâneos no poder infinito do espírito e na progressão constante do conhecimento, ele opõe a instabilidade, caducidade e incerteza de todo saber" (Idem, p. 48). Para Montaigne, o homem não ocupa um lugar privilegiado na criação. Afinal, como indica Hugo Friedrich, "a idéia de humanidade de tipo romano e humanista, que cerca a dignidade essencial do homem com precisão e firmeza para fazer a sua educação, desapareceu dos Ensaios" (Friedrich 4, p. 105). Quer dizer, a perspectiva humanista não dá conta do projeto intelectual montaigniano, o que poderia nos levar a questionar se no limite Montaigne pode ser considerado um filósofo humanista.

Outra perspectiva possível é a de considerá-lo como um precursor da filosofia vindoura uma vez que sua influência sobre Descartes e Pascal, por exemplo, é incontestável. Deste ponto de vista, Montaigne seria um elo entre a crise dos anseios renascentistas e o surgimento do homem e do pensamento modernos. Não foram poucos os que seguiram esta via. Entretanto, fazer isto significaria transformar Montaigne num mero filósofo de transição, responsável pelo desfraldar das cortinas para que a grande filosofia pudesse entrar em cena. Significaria, portanto, negar-lhe originalidade e decidir que sua posição filosófica não teria força suficiente para se sustentar. Montaigne teria, simplesmente, limpado o terreno da tradição para que Descartes pudesse, no século XVII, refundar o saber, salvaguardando o pensamento da tirania da dúvida.

Tais dificuldades de enquadramento da filosofia montaigniana não impediram, contudo, que uma leitura forte de sua obra se cristalizasse. Pós-humanista ou pré-moderno, Montaigne marcou história como um representante legítimo do ceticismo. Não é por acaso que a imagem de Montaigne como um filósofo refugiado em seu castelo, entretido com a intimidade de seus pensamentos, suspenso na dúvida cética e apoiado no passado literário clássico, sintetiza uma leitura recorrente de seu projeto intelectual. A retirada consciente e decidida da vida pública marcaria sua entrada na vida do espírito, já que a dolorosa perda do amigo La Boétie obrigara o filósofo a buscar abrigo na cidadela interior, arduamente apaziguada pelo trabalho da escrita. Longe das aparências, a salvo do baile de máscaras da vida social, Montaigne aceitaria dividir sua intimidade apenas com a companhia segura e sincera dos livros que o ajudariam, enfim, a reconstruir a identidade perdida. Evidentemente, esse movimento de reclusão e de reconstrução de si estaria garantido por sua posição social. Afinal, "não há intimismo sem privilégio de classe" (Arantes 2, p. 69-73). Os Ensaios seriam, pois, o testemunho do nascimento do intelectual moderno, por um lado, incapaz de engajar-se na vida concreta e mesquinha dos homens e, por outro, comprometido com o cuidado de si e com a manutenção da paz interior que só o desapego a qualquer dogma pode trazer.

Alguns dados da biografia de Montaigne corroboram para essa leitura. 
Afinal, muitos eventos produzem no filósofo uma aversão confessada à instabilidade da vida pública e o amor pelo prazer da intimidade e do ócio. Seu casamento se devera às conveniências; não há indícios de que tenha sido um pai muito presente; seu lugar no parlamento fora comprado pela família; o título de nobreza, pelo avô. Consta ainda que, provavelmente, seus ancestrais tenham sido judeus refugiados da Espanha, e que buscaram asilo na França. Nenhum terreno fixo, nenhuma tradição forte, nada que possa lhe fornecer estabilidade social ou de crença. Em suma, ninguém mais do que Montaigne poderia representar a figura do "homem dinâmico", descrita por Agnes Heller. Ninguém menos apto para sustentar os ideais renascentistas, tais como os formulados pela pena de Pico della Mirandola.

Cabe perguntar, entretanto, se essa areia movediça não constituiu o solo fértil de uma filosofia potente, cuja força crítica fora capaz de alterar os signos do humanismo em suas principais referências colhidas da antiguidade clássica. Nestes termos, nem mesmo o ceticismo - traço decisivo da imagem que herdamos de Montaigne - estaria a salvo de uma elaboração pessoal. Em suma, nas três correntes filosóficas importantes que cercam a formação intelectual de Montaigne - o estoicismo, o ceticismo e o epicurismo - perceberíamos o quanto a apropriação de tais elementos está sujeita a uma crítica refinada que propiciou a formulação de um humanismo próprio a Montaigne.

É preciso apagar da imagem tradicional de Montaigne a idéia de que o refúgio buscado na escrita encontra como amparo a segurança de uma cidadela interior. Ora, para desfazer tal imagem, ou pelo menos nuançar os detalhes ocultos pela simplificação que ela representa, é necessário compreender com mais profundidade os passos que levaram à formulação daquilo que realmente constitui a originalidade filosófica de Montaigne: a forma ensaio. É preciso, pois, rememorar a gênese da retirada ao castelo e mostrar que a solidão não garante inicialmente qualquer tipo de estabilidade. Conseqüentemente, é preciso mostrar que o ideal estóico de sabedoria é a primeira ilusão abandonada por Montaigne. A ataraxia estóica se sustenta na compreensão segundo a qual é possível circunscrever sabiamente um universo interior, um "eu", ou, como formulara Marco Aurélio, uma "cidadela interior" alheia aos apelos das paixões e indiferente aos caprichos da Fortuna:

Circunscrever-se, delimitar-se a si próprio, é praticar este triplo exercício: é, na ordem do assentimento, não aprovar os juízos de valor que sejam influenciados pelo corpo ou pelo sopro vital (que não nos concernem); é, na ordem do desejo, reconhecer que tudo o que não depende de minha escolha moral me é indiferente; é, na ordem da ação, ultrapassar a inquietação egoísta do corpo e do sopro vital, para se elevar ao ponto de vista da Razão, comum a todos os homens, e, portanto, querer o que é útil ao bem comum (Hadot 7, p. 136).

Ora, nenhum destes exercícios é admitido por Montaigne. Em primeiro lugar, porque o eu descrito nos Ensaios é encarnado. Mais que isso. A idéia de indiferença aos apelos do corpo só se sustenta no estoicismo devido uma concepção precisa de transcendência, inaceitável para Montaigne. Michael Screech, em seu importante estudo sobre a formulação da sagesse montaigniana como recusa das vias da transcendência (platônica, estóica ou religiosa), mostra que o êxtase pressupõe a aceitação de uma alma substancial, livre e soberana em relação ao corpo, capaz de ultrapassá-lo pelo trabalho do pensamento, da arte e da contemplação. Ora, basta dar uma olhada nos principais capítulos dos ensaios - mesmo naqueles em que o estoicismo comparece com mais vigor - para notarmos que o "eu" de Montaigne é mistura de corpo e alma, cuja costura é impossível desatar sem que se desfaça nossa humanidade.

Isto traz conseqüências importantes. No que concerne à sagesse propagada pelos Ensaios, a correção moral não poderá fazer apelo às vias da transcendência nem, muito menos, adotar como modelo a recusa das paixões como característica dominante do sábio. O estoicismo crê que, na ordem do assentimento, ou seja, na formulação de nossas idéias verdadeiras, o sábio é capaz de aceitar apenas as representações que o tocam de maneira evidente. A sabedoria pressupõe, portanto, a representação objetiva ou adequada da realidade e impede que juízos provenientes das perturbações do corpo e das paixões obscureçam o assentimento. Quer dizer, é na cidadela interior - onde reside a parte diretriz da alma e a liberdade de assentir e dar valor ao que nos é externo - que se configura o que está em nosso poder e conseqüentemente nos define. Portanto, é a partir de sua soberania e liberdade que o homem pode elevar-se à Razão universal (fonte do bem comum) e recolher-se ao ponto de vista do presente, evitando assim as inúteis preocupações com o passado e o futuro, que não estão em nosso poder e, portanto, não nos 
concernem. Jean Starobinski foi o responsável por mostrar como se deu o abandono desse ideal de vida regrada e apática, sustentado pela reclusão à vida interior e pela indiferença em relação ao exterior. $\mathrm{O}$ autor pondera que, em Montaigne, há um processo que vai da tentativa frustrada de seguir os exempla estóicos à formulação de uma manière própria de correção. Assim, a sagesse montaigniana aceitará o desafio de lidar com as mazelas do corpo (que inevitavelmente atingem a alma) e com o desregramento imposto pela Fortuna e pelas paixões.

Além disso, é preciso salientar que a solidão jamais se configura plenamente nos Ensaios. Lembremos que, já na abertura do livro, Montaigne delimita o alcance inusitado de sua empreitada: "sou eu mesmo a matéria de meu livro" (Montaigne 14, p.4). Trata-se de uma busca voraz da própria identidade. Entretanto, paradoxalmente, essa dissecação de si exige a figura de um outro a espreitá-la e a conferir-lhe solidez. A retirada ao castelo anunciava evidentemente que o amigo (encarnado na emblemática figura de La Boétie) era o paradigma de associação virtuosa reivindicado pelos Ensaios. No entanto, essa figura, desde o início da escrita da obra, anunciava-se como ausência. De fato, enquanto a Fortuna o permitiu, Montaigne vivera uma amizade plena ao lado de La Boétie. Sem temer a hipérbole, afirma-nos o filósofo: "Desde o dia em que o perdi (...) não faço senão me arrastar languescente; e os próprios prazeres que se me oferecem, em vez de consolar-me, redobram a tristeza de sua perda" (Montaigne 14, p.288). O primeiro passo para vencer a dor foi o "gesto teatral" de retirada para o castelo. Montaigne afastase dos afazeres públicos, da vita activa, e encontra apoio na terapia do otium cum literis. E, no intuito de vencer a melancolia, busca recuperar a identidade perdida - a constância virtuosa que a amizade de La Boétie incitava - através da escrita. Entretanto, a relação passada há de ser presentificada pela obra, ou seja, a associação virtuosa será encarnada no e pelo livro.

Ora, a reivindicação da presença do amigo como alteridade ideal confere um escopo preciso à sagesse buscada pelo ensaio - a sagesse montaigniana se realizará na associação e na comunicação:

requerendo a comunicação, pedindo a aquiescência da testemunha (leitor, espectador do retrato), a exigência estética abre a possibilidade de uma nova ética - ética que não encerra o indivíduo no dever da silenciosa autarcia, mas que o destina à exigência da veracidade na representação que faz de si a um destinatário exterior e que o obriga a buscar em outrem a garantia de sua presença para si mesmo (Starobinski 19, p. 36).

Quer dizer, embora o conhecimento de si arraste o filósofo para a solidão, em nenhum momento a investigação priva-o do convívio, já que a alteridade é essencial para a construção da identidade e da sagesse buscadas pelos Ensaios. Conseqüentemente, é preciso salientar que a afirmação da fraqueza do espírito humano para alcançar uma verdade absoluta (o famoso ceticismo de Montaigne) não o impele à renúncia do saber, na medida em que os Ensaios pretendem construir uma sagesse que não mais se consolida pela fé, pela sabedoria divina ou pelo pressuposto de uma ordem racional universal acessível ao sábio. É neste ponto que surge o empreendimento ensaístico como construção positiva de um saber mediado pela constante referência à alteridade.

Em linhas gerais, "essai” significa exame, tentativa, esboço, esforço, procura. Nos termos de uma ciência experimental, o ensaísta seria, grosso modo, aquele que submete os dados naturais à experimentação e mede os efeitos obtidos. Porém, transposta para as realidades morais e espirituais, e suas possíveis pesquisas, a palavra ganha uma diferente gama de sentidos em Montaigne e em Bacon. O último, no Novum Organon (II, 10 e anexo final), propõe a passagem da experiência - vaga ou errante - ao experimento - ou ensaio lucífero e frutífero - e para isso apresenta a idéia de uma "História Natural e Experimental" que sirva de base à "verdadeira filosofia". Em outras palavras, introduz a idéia de método ou de tratamento metódico da experiência (o experimento) como condição da indução adequada ao conhecimento verdadeiro. Mais tarde, no Ensaiador, Galileu apresenta a idéia do ensaio como passagem da experiência imediata (sensorial, espontânea, aleatória) ao experimento ou à experiência dirigida e controlada pela razão e auxiliada pelos instrumentos técnicos (luneta, balança, plano inclinado etc.). Tanto para Bacon como para Galileu, a experiência dirigida e controlada deve ser longa e circunstanciada para que dela provenha uma ciência da natureza. Embora, como estes últimos, Montaigne também pratique a idéia de experiência longa e circunstanciada, em Bacon e Galileu as circunstâncias são controladas. Já para Montaigne elas constituem, de um lado, o campo da Fortuna e, de outro, saberes que procuraram 
cercar a própria Fortuna, isto é, a tradição, cuja diaphonia repõe a Fortuna. Quer dizer, em Bacon e Galileu, o ensaio é controle metódico sobre a natureza; em Montaigne, encontro, embate, percurso que pesa opiniões próprias e alheias. Em Bacon e Galileu, o outro, isto é, a natureza, deve ser subjugada pelo conhecimento; em Montaigne, o outro é a mediação para acercar-se de si mesmo. Em Bacon e Galileu, a alteridade é o objeto do ensaio; em Montaigne, o ensaio é reflexivo e seu objeto é o próprio ensaiador ou ensaísta. Mais do que encontro com um eu pressuposto, o ensaio é experiência de nossa própria mobilidade e da mobilidade de tudo que nos cerca e atinge. Assim, a investigação deve oscilar de acordo com as mudanças no olhar do ensaísta e de acordo com a fluidez da experiência. Daí que Montaigne se recuse a caracterizar seu trabalho como método, dada a rigidez que o termo implicaria.

Cabe lembrar aqui o artigo de Adorno "O ensaio como forma", pois este salienta que a dúvida sobre o direito absoluto do método só se realizou no ensaísmo. Segundo o filósofo alemão, o ensaio não entende as condições do conhecimento como estáveis e controláveis. Neste sentido, o ensaísta tem consciência da "não-identidade" do sujeito e do objeto. Essa consciência imprime ao ensaísmo um ilimitado esforço de exposição. Então, o aspecto assistemático, fragmentado, fortuito, ametódico do ensaio se converte num rigor de outra ordem, já que o como da exposição tem de salvar, enquanto precisão, o que é sacrificado pela renúncia às definições rígidas, para que não se submeta o objeto à arbitrariedade de significações conceituais decretadas de uma vez para sempre. $\mathrm{O}$ ensaio exige, mais do que o procedimento de definição ou de conceitualização, a interação dos conceitos no processo da experiência espiritual. Nele, os conceitos não constituem um contínuo operativo e metódico; ao contrário, eles se apresentam como momentos que se entretecem como os fios de uma tapeçaria. A fecundidade do pensamento - afirma Adorno - depende da densidade desse tecido. Ora, esta preocupação aparece em Montaigne através de formulações como: “À medida que meus devaneios se apresentam, vou amontoando-os; ora eles se precipitam em bando, ora se arrastam em fila. Quero que vejam meu andamento natural e habitual, tão desencontrado quanto é” (Montaigne 15, p. 116). Isto significa que Montaigne escreve porque quer conhecer-se e fazer-se conhecer. Para tanto, não é necessário que fale somente de si, porquanto os Ensaios “o representam, ainda que nada digam dele mesmo" (Tournon 20, p.79). Quer dizer, o alvo da empreita -

Michel de Montaigne - não se revela apenas naquilo que diz de si mesmo:
A reflexão que se inscreve na obra inspeciona os relevos e marcas da identidade do escritor enredados no seu movimento mesmo de abertura para o mundo, na aplicação de seu pensamento às mais diversas matérias, nas múltiplas modalidades de sua atuação: quer descreva, aprecie ou especule, quer deseje, rejeite ou delibere, em vista de qualquer assunto ou objeto, o autor observa-se e testemunha a si mesmo, pois manifesta nestes atos algum traço de sua constituição (...) qualquer ação é apropriada para dá-lo a conhecer (Cardoso 3, p.52-3).

Ora, é nessas e noutras "aberturas para o mundo" que o papel da alteridade surge como o que possibilita a elaboração reflexiva dos Ensaios.

Quer dizer, ao mesmo tempo em que nega, por um lado, a via da transcendência, e, por outro, a rigidez do método, Montaigne estabelece uma relação lúdica com o exterior, aceitando a perturbação constante causada pelas aparências. Neste sentido, longe de se conceber como um especialista das humanidades, Montaigne representa a figura do intelectual que nega a divisão de trabalho, que defende a livre investigação e a liberdade nas relações sociais pautadas pelo paradigma da amizade e do encontro. Sendo assim, ele não se conforma à leitura de Horkheimer que encontra em Montaigne o representante da nova nobreza, os burgueses adaptados, incapazes de utopia e inimigos da revolução. Assim como Adorno, Horkheimer é um crítico do intelectual profissional, fruto da separação social entre teoria e prática. Entretanto, porque frisa o aspecto cético e desinteressado do pensamento montaigniano, o filósofo não pode encontrar nos Ensaios o potencial crítico reconhecido por Adorno. Quando o último fala em degeneração da forma, indica que, no seu início, o ensaio guardava um poder crítico exatamente porque seu procedimento impedia a separação entre teoria e prática, uma vez que o ensaio mantinha constante a relação entre conceito e objeto, impossibilitando assim a hipóstase do conceito. $\mathrm{O}$ ensaio esforça-se por dar voz à natureza e à alteridade na medida em que não assevera a identidade entre conceito e objeto, ou a dominação de um pelo outro. Conseqüentemente, segundo Adorno, a forma ensaio, por um lado, não admite a figura do intelectual indiferente ao exterior e, por outro, exige que se considere o caráter 
histórico imanente ao conceito. Para Horkheimer, entretanto, Montaigne - o aristocrata cético - é uma espécie de intelectual Sancho Pança alheio aos problemas de seu tempo.

Evidentemente, Montaigne não é um revolucionário (e exigir dele tal postura não passa de puro anacronismo). Entretanto, visto o que dissemos até aqui, cabenos reconhecer que o "eu" de Montaigne e seu estilo de apresentação não podem ser lidos nem como adesão imediata ao real, nem como puro conformismo sustentado pelo gozo de uma liberdade interior. Horkheimer, porque nega tais características do ensaísmo montaigniano, parece exigir de Montaigne o que Sartre exigia de Merleau-Ponty: definirse ou como um filósofo que se engaja e livremente toma partido, ou como um mero profissional da academia ou um diletante. Contra essa exigência, Merleau-Ponty pondera: "Há ocasiões (...) em que a vida em parte dupla cessa de ser possível, em que o interior e o exterior não se distinguem" (Merleau-Ponty 13, p. 229). Somente uma concepção da subjetividade pautada no dualismo entre corpo e alma e na liberdade de um ego centrado pode conceber a ação humana como incondicionada e, conseqüentemente, indiferente aos apelos do corpo e da Fortuna. Ora, o ensaísmo é, tal como define Adorno e como pratica Montaigne, a recusa desta concepção. Neste sentido, Montaigne não é apenas um herdeiro crítico do humanismo renascentista mas - podemos dizê-lo retrospectivamente, de acordo com o diagnóstico merleau-pontiano - um crítico da longa tradição moderna, nascida com Descartes, que concebe o sujeito como um ser desencarnado cuja ação não envolve qualquer ambigüidade. Conceber a força crítica do ensaísmo exige, portanto, que sejam revistos não apenas o contexto no qual surge o pensamento de Montaigne (ou seja, o Renascimento e a figura do humanista) mas também os paradigmas dualistas segundo os quais a Modernidade concebeu a experiência de pensamento.

\section{Montaigne's sagesse as critical apropriation of humanist heritage}

Abstract: The Renaissance's thought was responsible for a vigorous reflection on the metaphysical man's standing in the cosmos and on the action's role in the social life. Taking into account this context, this paper intends to debate on Montaigne's thought, regarding its link as well its divergences from humanist thought, especially these divergences that made possible the development of the peculiar philosopher's manière: the essay form.

Keywords: Montaigne, humanism, Renaissance, essay.

\section{REFERÊNCIAS BIBLIOGRÁFICAS}

1. ADORNO, T. W. "El ensayo como forma" in Notas de literatura. Trad. de M. Sacristán, Barcelona: Ediciones Ariel, 1962.

2. ARANTES, P. E. "Quem pensa abstratamente?" in O ressentimento da dialética. Rio de Janeiro: Paz e Terra, 1996.

3. CARDOSO, S. "O homem, um homem: do humanismo renascentista a Michel de Montaigne". In: Sociedade Brasileira de Psicanálise de São Paulo (org.). Perturbador Mundo Novo. São Paulo: Escuta, 1992.

4. FRIEDRICH, H. Montaigne. Paris: Gallimard, 1968.

5. GARIN, E. Ciência e vida civil no Renascimento italiano. Trad. de Cecília Prada. São Paulo: Ed. Unesp, 1996.

6._. Moyen Age et Renaissance. Paris: Gallimard, 1969.

7. HADOT, P. La Citadelle Intérieuse. Introduction aux Pensées de Marc Aurèle. Paris: Fayard, 1992.

8. HELLER, A. O homem do renascimento. Lisboa: Inquérito, 1972.

9. HORKHEIMER, M. Teoria Critica. Barcelona: Barral Editores, 1973.

10. KRAYE, J. "Moral Philosophy" in Schmitt et Skinner et Kessler (org.). Cambridge History of Renaissance Philosophy. Cambridge: New York: Cambridge University Press, 1988.

11. KRISTELLER, P. O. Ocho filósofos del renacimiento italiano. Trad. de M. M. Peñaloza. Madrid: Fondo de Cultura Económica, 1996.

12. _. Tradição clássica e pensamento do Renascimento. Lisboa: Edições 70, 1995.

13. MERLEAU-PONTY, M. Signos. Trad. de M. G. Pereira. São Paulo: Martins Fontes, 1991.

14. MONTAigne, M. Os Ensaios, I. Trad. de R. Abílio. São Paulo: Martins Fontes, 2000.

15. Os Ensaios, II. Trad. de R. Abílio. São Paulo: Martins Fontes, 2000.

16. NAKAN, G. Montaigne et son temps. Paris: Gallimard, 1993.

17. PICO DELLA MIRANDOLLA, G. Discurso sobre a dignidade do homem. Trad. de M. de Lurdes S. Ganho. Lisboa: Edições 70, 1998.

18. SCREECH, M. A. Montaigne et la melancolie. Trad. F. Bourgne. Paris: PUF, 1992.

19. STAROBINSKI, J. Montaigne en Mouvement. Gallimard: Paris, 1982.

20. TOURNON, A. Montaigne en toutes lettres. Paris: Bordas, 1989.

\section{NOTAS:}

1 - A expressão é de G. Nakan. 